\title{
Psycho-social Impact of COVID 19 Pandemic on University Students of Himachal Pradesh
}

\author{
Madhur Katoch*, Raj Pathania and Goldy Chopra \\ Department of Human Development and Family Studies, College of Community Science, CSKHPKV, Palampur, India
}

*Corresponding author: madhur.katoch@gmail.com (ORCID ID: 0000-0003-0087-6574)

Received: $14-10-2020$

Revised: 24-01-2021

Accepted: 25-02-2021

\begin{abstract}
College students are recognized as a vulnerable population these days who suffer from varied levels of anxiety, depression, substance abuse, disrupted eating and sleeping patterns as compared to general population. Therefore, when the nature of their daily life and educational experience changes like during the COVID-19 pandemic - the weight of mental health of this vulnerable population is magnified. The objectives of this study were to assess the impact of Covid 19 pandemic on psycho-social health of University students. Questionnaires were mailed to Under Graduate students of CSKHPKV, Palampur students. A total of 160 responses were received and results were interpreted. The results revealed that 45 per cent respondents experienced severe anxiety, followed by ( $42.5 \%$ ) who had moderate level of anxiety. On the other hand, 58.7 per cent experienced moderate level of stress during lockdown. No significant difference was found between male and female students regarding anxiety and stress. A positive correlation was observed between age and anxiety among respondents. Lockdown resulted in increased frustration due to uncertainty characterising immediate future plans, academic stress and feelings of helplessness among students.
\end{abstract}

\section{Highlights}

(0 Students were found to suffer from severe to moderate Anxiety disorder during lockdown.

0 More than half of the sample experienced Stress related to academics, social isolation and infection

0 Increase in Conflicts with parents, frustrations and changed sleeping patterns were also experienced.

( Weekly Advisory classes are not enough to fight the Mental health issues, need of setting up of Psychological counselling centre by administration is required.

Keywords: Psycho social problems, anxiety, stress, college students, pandemic

The novel corona virus (COVID-19) pandemic caused massive disruptions to everyday life. The World Health Organization (WHO) declared COVID-19 outbreak as a pandemic on March 11, 2020 (WHO, 2020). The first COVID-19 case was reported in Kerala, India on January 30, 2020. A nationwide lockdown was imposed on 24 March 2020 by Government of India under Prime Minister Narendra Modi for 21 days, limiting movement of the entire 138 Crore population of India as a preventive measure against the COVID-19 pandemic in India. All public gatherings were prohibited; modes of public transport were shut down. The lock down was extended 4 time in total and India remained in lockdown for 75 days. All schools, colleges and Universities implemented preventive measures by closing campuses. Students residing in hostels moved

How to cite this article: Katoch, M., Pathania, R. and Chopra, G. (2021) Psycho-social Impact of COVID 19 Pandemic on University Students of Himachal Pradesh. Int. J. Soc. Sci., 10(01): 37-44.

Source of Support: None; Conflict of Interest: None 
back to their homes. In a short period of time the lives of students have changed dramatically as they have to adjust to new living circumstances. Teaching was shifted to online-based teaching/learning curriculum postponing examinations etc. The sudden switch to online teaching and learning particularly in those courses that were more practical oriented created stress among students. Some students don't have access to computers or internet at homes. In addition to this lack of contact with friends and social isolation also add on to their distress by resulting in feelings of loneliness and frustration, which were reported to be difficult to cope with. College students also comes in conflict with their parents due to their close proximity all the time. Parental nagging also resulted in stress and feeling of helplessness.

Mental health of College students has become a rising concern with quite a significant number of students experiencing psychological distress especially during Covid times (Kecojevic et al. 2020).

Issues with mental health can effect motivation, concentration, future career opportunities and sociopersonal interactions. Maladaptive behaviours, emotional and defensive reactions were some of the psychological responses to pandemic (Taylor, 2019). Pandemic led to social isolation which is strongly associated with anxiety, worries, depressions and sometimes suicidal thought. Isolation, frustrations, and even boredom and even the stress of contacting virus and concern for family and friends, lack of freedom all these factors affect the mental well being during lockdown and quarantine. Poor sleeping and eating habits and psychological distress were also welldocumented during earlier pandemics (Chen et al. 2011). In particular, poor sleep was associated with negative emotions, depressive symptoms and increased risk of mental illness (Agargun et al. 1997). In a recent study conducted during the COVID-19 outbreak in India, one fifth of adults were found to suffer from depression and stress and one fourth from anxiety (Saikarthik et al. 2020) disrupted daily routine, poor eating and sleeping patterns and unplanned daily lifestyle among college students have led to poor and unhealthy coping strategies.
The main source of coping with feelings of helplessness or frustration are family and friends. Dhillon and Mishra (2020) reported that lockdown leads to enhanced family interactions but it also placed additional stress on those family units where relationships among couples or parent-child were already strained beforehand. Under such conditions, social media offered an important rescue to the students. Social media is a formidable source of support in the form of providing information and maintaining contact with friends and family. Social media provided face to face social support, in terms of online support groups, blogs and Face group or WhatsApp, but it also proffers a distinctive aspect in anonymity and non-judgemental interchange. On the other hand, for some it is more tiring and draining as it is not considered as a permanent solution to the problems but a temporarily halt to their family dynamics at home.

Although a large body of research from the west focussed on emerging mental health issues of adolescents or college going students, studies focussing on the Indian population remain scanty. The stigma attached to the mental problems or anxiety issues or worries or stress are considered as problems afforded by well off individuals. Despite the increasing need of mental health care services at higher institutions very few provides psychological counselling units at their campuses. Not only negative stigma attached to it but also the need for such problems is not recognised. This study also remitted a neglected area of psycho social impact of Covid 19 on the mental health of University students of Himachal Pradesh. Gathering of insights and youngsters' response in face of such pandemics, disasters or catastrophes will help us to look inside the lacunas in our system and what measures we need to take up to build resilience among children or youth so that they can deal with these mischance or setbacks with much strength and solidity.

\section{Methodology}

Sample and sample size: Under Graduate students in the age group of 18-23 years formed the sample for the study. A sample size of 160 formed the total sample for the study. Online administration of tools was done. Out of 160, 92 were female and 68 were male students. 
Method of data collection: The questions were uploaded on Google forms and were mailed to the to the Under Graduate students of State Agricultural University i.e. CSK HPKV, Palampur. The students were briefed on the purpose, anonymity and confidentiality of their responses. A total of 178 responses were received back. Out of these only 160 were complete and the remaining which did not fill the criteria were not included into the study. Therefore, a total of 160 students were studied for the psycho social problems.

Tools used for the study: The questionnaires used for the study consists of Generalized Anxiety Disorder 7-item (GAD-7) scale. Scoring Scores of 5, 10, and 15 are taken as the cut-off points for mild, moderate and severe anxiety, respectively. When used as a screening tool, further evaluation is recommended when the score is 10 or greater. Using the threshold score of 10 , the GAD-7 has a sensitivity of $89 \%$ and a specificity of $82 \%$ for GAD. It is moderately good at screening three other common anxiety disorders - panic disorder (sensitivity $74 \%$, specificity $81 \%$ ), social anxiety disorder (sensitivity $72 \%$, specificity $80 \%$ ) and post-traumatic stress disorder (sensitivity $66 \%$, specificity $81 \%$ ).

In order to understand the psycho social problems experienced by students another tool, a semi- structured questionnaire comprising of 12 questions (Likert scale)was drafted. The questions included emotional reaction to Covid 19, interactions with parents and family members, stress related to online classes, covid infections, social anxiety, everyday routine problems and difficulties. Eight open ended questions were also formulated to understand the effect of lockdown on daily routine and how it is affected. Along with it role of social media and stress related questions were included to generate the qualitative data.

\section{Data analysis}

After the responses were generated, the information was tabulated and computed. The tables were quantified using frequency and percentages were calculated. Data was further subjected to statistical analysis by using appropriate test.

\section{RESULTS}

The mean age of total sample of respondents was 20.68 years $(\mathrm{SD}=1.494)$. A shown in Table 1, it is found that 51.3 per cent of the respondents belonged to the age group of 21-23 years and the remaining 48.7 per cent were from the age group of 18-20 years.

Table 1: Age wise distribution of the respondents

\begin{tabular}{lll}
\hline Age & $\begin{array}{l}\text { Number of } \\
\text { respondents }\end{array}$ & $\begin{array}{l}\text { \% wise } \\
\text { distribution }\end{array}$ \\
\hline 18-20 years & 78 & 48.7 \\
$21-23$ years & 82 & 51.3 \\
\hline Total & $\mathrm{N}=160$ & 100.0 \\
\hline
\end{tabular}

It is evident from the Table 2 that 57.5 per cent of respondents were female and remaining 42.5 per cent were male respondents.

Table 2: Gender wise distribution of the respondents

\begin{tabular}{lll}
\hline Gender & $\begin{array}{l}\text { Number of } \\
\text { respondents }\end{array}$ & $\begin{array}{l}\text { \% wise } \\
\text { distribution }\end{array}$ \\
\hline Male & 68 & 42.5 \\
Female & 92 & 57.5 \\
\hline Total & $\mathrm{N}=160$ & 100.0 \\
\hline
\end{tabular}

Table 3 depicts the severity of Anxiety disorders among University students. It is clear from the table that 45 per cent experience severe anxiety, where $(48.9 \%)$ were found to be female respondents and remaining 39.9 per cent were male respondents. It was followed by $(42.5 \%)$ who had moderate level of anxiety disorder where more than half i.e. 52.9 percent were male students and remaining 34.7 per cent were female students. Further it is revealed from the table that only 12.5 per cent of respondents had mild level of anxiety disorder during the lockdown period.

Table 3: Distributions of respondents on the basis of General Anxiety Level disorder

\begin{tabular}{llll}
\hline $\begin{array}{l}\text { Levels of } \\
\text { anxiety }\end{array}$ & $\begin{array}{l}\text { Male } \\
(\boldsymbol{n}=\mathbf{6 8 )}\end{array}$ & $\begin{array}{l}\text { Female } \\
(\boldsymbol{n}=\mathbf{9 2})\end{array}$ & $\begin{array}{l}\text { Total } \\
(\boldsymbol{N}=\mathbf{1 6 0 )}\end{array}$ \\
\hline Mild & $5(7.3)$ & $15(16.4)$ & $20(12.5)$ \\
Moderate & $36(52.9)$ & $32(34.7)$ & $68(42.5)$ \\
Severe & $27(39.8)$ & $45(48.9)$ & $72(45.0)$ \\
\hline Total & $68(100.0)$ & $92(100.0)$ & $160(100.0)$ \\
\hline
\end{tabular}

Figure in parentheses represents percentages. 
$\underset{\text { AESSRA }}{W_{W}}$ Katoch et al.

Table 4: Distribution of respondents on the basis of perceived Stress

\begin{tabular}{llll}
\hline $\begin{array}{l}\text { Levels of } \\
\text { anxiety }\end{array}$ & $\begin{array}{l}\text { Male } \\
(\boldsymbol{n}=\mathbf{6 8})\end{array}$ & $\begin{array}{l}\text { Female } \\
(\boldsymbol{n}=\mathbf{9 2})\end{array}$ & $\begin{array}{l}\text { Total } \\
(\boldsymbol{N}=\mathbf{1 6 0 )}\end{array}$ \\
\hline Low & $15(22.0)$ & $26(28.3)$ & $41(25.6)$ \\
Moderate & $46(67.7)$ & $48(52.1)$ & $94(58.7)$ \\
High & $7(10.3)$ & $18(19.6)$ & $25(15.7)$ \\
\hline Total & $68(100.0)$ & $92(100.0)$ & $160(100.0)$ \\
\hline
\end{tabular}

Figure in parentheses represents percentages.

Table 4 reveals the distribution of respondents on the basis of stress among male and female students of University. It can be seen from the table that 58.7 per cent experienced moderate level of stress during lockdown, where more than half of male respondents $(67.7 \%)$ and $(52.1 \%)$ were female respondents. It is followed by $25.6 \%$ of respondents who had low level of stress related to academic, social or familial relationships. Where 15.7 percent demonstrated high level of stress during this period of social isolation.

Table 5: Effect of Age on scores of Anxiety and Stress

\begin{tabular}{lll}
\hline Scores & Pearson Coefficient $(\boldsymbol{r})$ & P-value \\
\hline Anxiety & $0.3186^{*}$ & $\mathrm{P}<0.001$ \\
Stress & 0.006194 & 0.3225 \\
\hline
\end{tabular}

$r=$ correlation coefficient ${ }^{*}$ Significant at $1 \%$ level of significance.

It is clear from table 5 that age is positively correlated with anxiety disorders, where no significant relationship was observed for stress. It was assumed that students having feeling of anxiousness during these unprecedented times seems relevant because anxiety is defined as having generalised feeling having reference to vague feelings and thoughts, without understanding the exact cause. Table 6 studied the effect of gender on anxiety and stress among university students. It is revealed from the table that there is no significant correlation between gender and anxiety and stress.

Table 6: Effect of Gender on scores of Anxiety and Stress

\begin{tabular}{lll}
\hline Scores & Pearson Coefficient $(\mathbf{r})$ & P-value \\
\hline Anxiety & -0.002689 & 0.9731 \\
Stress & 0.08597 & 0.9141 \\
\hline
\end{tabular}

$r=$ correlation coefficient.
Table 7 shows that there is no significant difference between male and female students with respect to the anxiety and stress. It can be assumed that as both were going through the same situation no specific gender differences were found.

Table 7: Gender difference in scores of Anxiety and Stress

\begin{tabular}{lll}
\hline Scores & Unpaired $\mathbf{t}$ test & P-value \\
\hline Anxiety & 0.03380 & 0.4050 \\
Stress & 0.1485 & 0.230 \\
\hline
\end{tabular}

$F=1.059(\mathrm{NS}), F=1.180(\mathrm{NS})$.

About 8 open ended questions were also asked to collect qualitative data from the students regarding affect on their study pattern and sleep pattern and their daily routine, the relationship with their parents or other family members, importance of social media, social isolation from friends, concerns about contracting the virus etc. These questions gave an overall view of the status of their minds at that particular time.

I feel stuck inside.... for few days it was relaxing but now I am getting restless and bored.

The unprecedented nature of this pandemic and its impact on the lives of people even for very small things like going out of the house or meet friends and family or eating out resulted in the feelings of helplessness and frustration at times. Even the same routine of sitting inside homes has made people restless and anxious at times.

Though I enjoy watching movies or scrolling through social media. But I'm getting bored now. Online classes are going on but sometimes signal problems or internet facility affects my studies also. I am also concerned about my future.

Social media play an important role in today's times. Not only it keeps one updated about recent developments but it also provides an opportunity to express one self. It has made the world small but also it has created distances among people. Nowadays youngsters or even adults are addicted to their mobiles. Many researches also suggest the ill effects of excessive use of social media. It leads to worries or anxieties among people. Continuous scrolling makes one dull and bored. In times of pandemic social media has been a boon to many. Not only it helped in 
online education but also helps respondents in contact with their friends. But many respondents suggested that offline mode of education is much better than online teaching. Many have problems related to internet connection or the lack of discussion in class.

I like living in hostel.as now I'm with my parents they constantly keep on bickering to keep my room clean, get up at time..less screen time and many more. It is as if I don't have privacy any more.

For some of the respondents the effect of lock down was different. They reported that their relationship with parent has improved. Constantly living with them day and night resulted in closeness and less conflict. They played games, eat together, watch movies etc. But for some especially who are more independent feel lack of privacy and scoldings from parents make their lockdown a little tough. The close vicinity of parents led to certain disagreements between respondents and their parents.

My mother is a nurse and we all were scared for her wellbeing. She has to remain in hospital for some days and when she is at home we are not in direct contact with her. It was very stressful for all of us. I fear that she will catch infection and something will happen to her. I lived in constant stress. Even the news channels created chaos regarding this pandemic. Listening to news channels is stressful

The threat of infection being passed to family members is a source of stress among respondents. They were worried about their family members. Media also plays an important role in public domain where news regarding Covid 19 morbidities and mortality rate effect the stress level among people. Influx in the news during lockdown and havoc created by some irresponsible media channels results in stress, frustration and pessimism. Watching news also supplemented their stress.

\section{DISCUSSION}

The outbreak of corona virus has led to various changes and has substantially influenced the life of many people. Among these people is the category of University students. The experience of home quarantine under lockdown especially in a country like ours where we remained in complete lockdown for 75 days is really taxing physically and mentally. But for University students especially Under Graduates they were not allowed to come for another 8 months. Therefore, they remained at homes for approximately one year without attending offline classes. Lockdown not only posed threat to economy but also impacted the mental health of the people. Paranoia about acquiring infection and sleep difficulties were reported among $37.8 \%$ and $12.5 \%$ of participants. These people felt the growing need of mental health care (Roy et al. 2020). According to (Loiwal, 2020) one in every five people was afflicted by mental health issues during that time. In a similar study conducted by Garg et al. (2020) analysis of data using Perceived Stress Scale (PSS) revealed that 19.4\% participants had low and $80.6 \%$ had moderate perceived stress.

In a similar study conducted by Islam et al. (2020) among University students during covid 19 pandemic in Bangladesh revealed that $82.4 \%$ students were found to have mild to severe anxiety symptoms. More than $60 \%$ were male $(67.2 \%)$ and rest were female. In another study conducted by Biswas \& Biswas (2020) who assessed the anxiety levels using GAD - 7 among students of different Colleges and Universities in India during lockdown in connection to the Covid 19 pandemic. Their results revealed that female students are more anxious than male students. Son et al. (2020) conducted an assessment on the effects of Covid 19 pandemic on the mental health of college students from University system in Texas in US. Out of 195 students $71 \%$ (138) showed increased stress due to Covid 19. Majority that is 82 per cent were found concerned about academic performance.

Dhillon and Mishra (2020) assessed the psycho social impact of Covid 19 pandemic on young Indians. The result revealed that lockdown had affected the respondents sense of agency urgently, where they felt helpless in their homes that resulted in the feelings of loneliness and isolation. Large scale disasters like natural disasters, environmental catastrophes terrorist attacks or wars have serious mental health implications that includes increase in depressions, PTSDs and substance abusers (Neria et al. 2008). According to (Tracy et al. 2011) the SARC epidemics led to increased 
Post Traumatic Stress Disorder and increased psychological distress. Husky et al. (2020) conducted a study on university students in France during covid confinement. The sample experienced increased anxiety as well as moderate to severe stress during lockdown. Respondents who did not relocated to live with parents were significantly affected.

Problems related to mental health are the leading impediment to academic success. These problems can affect student's achievement motivation, attention, and social interactions, which are vital for students to succeed in higher studies. Annual Report of the Centre for Collegiate Mental Health delineated that anxiety is the most common problem experienced by (62.7\%)of respondents who completed the Counselling Centre Assessment of Psychological Symptoms. The clinician university counselling centres also reported that anxiety continues to be the most common diagnosis of the students that seek services. In 2018 , slightly over $50 \%$ of students reported anxiety as the main reason for seeking services.

The Corona Virus Disease 2019 (COVID-19) pandemic has become a causative factor that led to increase in fear, anxiety, stress, and depression among varied populations. Among these, university undergraduates from various countries of the world were most affected. As they faced strict lockdown measures, they have few resources to cope up with it. Hidalgo (2020) analysed the levels of fear, stress, depression and stress related to Covid 19 during lockdown among under graduate students from Ecuador. The mean levels found for stress, anxiety, and depression were above levels considered non-pathological. Female experiences higher levels of fear of COVID-19 than their male counterparts. The statistical prediction for depression showed a good fit. Many factors led to anxiety among college students, it can be sleep disruptions, eating disorders, academic stress, disengagement from studies, loneliness etc. these restrictions made students stressed and anxious than ever before. A study conducted by Leblance and Marques (2019) reported that there is a significant decrease in psychological wellbeing among adolescents. The cause is not clear, that what leads to this trend, but the research shows a strong association between time spent on social media and reduced well being. The excessive use of smartphone might be interfering with adjustment. Students don't have time for exercise, healthy face to face social interactions. They have even ignored their hobbies like reading, playing etc. and when these Covid 19 restrictions were imposed their time spent on smartphones either for online classes or use of social media to keep in touch with outside or their friend circle have added on to their problems. This might also be a causative factor.

As reported majority of the students experienced high to moderate anxiety and stress during these times. Therefore, universities must be well-equipped to address the mental health needs of their entire student body. Schlesselman et al. (2020) reported that, University of Connecticut and University of Kentucky, US have promoted mental health programmes for university students that include virtual group exercise, meditation/ mindfulness sessions, accountability buddies, exercise challenges and counselling visits. These programs may be helpful not only in lowering anxiety but also in decreasing the sense of isolation reported by the students.

\section{CONCLUSION}

Mental health is an important issue that concerns the youth nowadays, especially during the time of COVID-19. It has been a catastrophic experience as a whole. This dreadful pandemic abruptly changed the way we live. As reported earlier pandemics are expected to have undesirable consequences not only in terms of health but also on economic, political, and educational systems. Education systems are worst hit, students are facing uncertainty in academic and their future goals. University students in the final year are among the most affected as they are placed in industrial trainings for three months for practical experience. Due to restrictions imposed in end March 2020, they were forced to come back leaving their trainings/internships. As this pandemic is raising its head again partial closing of classes is again affecting their classes. All these factors increasing anxiety and stress among students. But as we fight this pandemic educational institutes must be prepared to deal with epidemics by establishing pre- 
outbreak policies and procedures. Mental health must be given priority. Psychological Counselling centres must be established in campuses and experienced counsellors be available online to deal with any problems associated with students. On the other hand, students must be sensitized to speak openly regarding issues related to mental health. Negative stigma attached to mental problems should be eliminated because students deserve inclusive, healthy environments that empower them to succeed in higher education and beyond University administrators could best serve students if they have better understanding of the impacts of COVID-19 pandemic and its impact on their mental health. These impacts are of vital significance to warrant immediate interventions for mental health that will help to focus on prevention and treatment of problems. As interpretation of results gave valuable insights into the psychological status of students at a crucial time, and this, of course, has its own merit. However, it is equally important that future researches identifying appropriate strategies that could help them to cope with effects of pandemic but also built resilience in the face of future disasters. Parents, educators and communities must be sensitized so that they help these youngsters to cope in such situations. Moreover, future researches may use large scale comparative cross generational studies to look at the mental health status of population. This will help the policy makers to develop risk management protocols to contain ill effects of future pandemics.

\section{REFERENCES}

Agargun, M.Y., Kara, H. and Solinaz, M. 1997. Sleep disturbances and suicidal behaviour in patients with major depression. J. Clin. Psychiatry, 58: 249-251.

Bai, Y.X., Gegan, T., Hai, H., Liu, Z.H., Wang, W.R. and Wang, Z.G. 2005. Correlation between psychological changes of the community crowd and the social support in grave public health event. Inner Mongolia Med. J., 37(4): 295-297.

Biswas, S. and Biswas, A. 2021. Anxiety level among students of different college and universities in India during lock down in connection to the COVID-19 pandemic. J. Pub. Heal., https:// link.springer.com/article/10.1007/s10389-020-01431-8

Brooks, S.K., Webster, R.K., Smith, L.E., Woodland, L., Wessely, S., Greenberg, N. and and Rubin, G.J. 2020 The psychological impact of quarantine and how to reduce it: rapid review of the evidence. Lancet, 395: 912-920.
Center for Collegiate Mental Health. University Park, PA: Penn State University. 2019 annualreport. https://ccmh. memberclicks.net/assets/docs/2019-CCMH-Annual Report_3.17.20.pdf.

Chen, W., Huang, A.S., Chuang, J., Chiu, C. and Kuo, H. 2011. Social and economic impact of school closure resulting from pandemic influenza A/H1N1. J. Infection, 62: 200-203.

Dhillon, M. and Mishra, V. 2020. Life in lockdown: The psychosocial impacts of the COVID 19 pandemic on young Indians. Indian J. Heal. and Well-being, 11(7-9): 324-330.

Hidalgo, A.J.R., Pantaleon, Y., Dios, I. and Falla, D. 2020. Fear of COVID-19, Stress, and Anxiety in University Undergraduate Students: A Predictive Model for Depression. Frontier Psychology. https://doi.org/10.3389/fpsyg.2020.591797

Holm-Hadulla, R.M. and Koutsoukou-Argyraki A. 2015. Mental health of students in a globalized world: Prevalence of complaints and disorders, methods and effectivity of counselling, structure of mental health services for students. Mental Health \& Prevention, Elsevier, 3: 1-4.

Husky, M.M., Masftey, V.K. and Swendson, J.D. 2020. Stress and anxiety among university students in France during Covid-19 mandatory confinement. Comprehensive Psychiatric https:// doi.org/10.1016/j.comppsych.2020.15219|

Islam, M.A., Barna, D., Raihan, H., Khan, M.N.A. and Hossain, M.T. 2020. Depression and anxiety among university students during covid 19 pandemic in Bangladesh: A web based cross sectional survey. https://doi.org/10.1371/journal.pone.0238162

Kecojevic, A., Basch,, C.H., Davi, N. and Sullivan, M. 2020. The impact of the COVID-19 epidemic on mental health of undergraduate students in New Jersey, cross-sectional study. https://doi.org/10.1371/journal.pone.0239696

Lal, H. 2020. Covid 19 in view of behavioural safety and health culture in India. Indian J. Heal. Well-being, 11(7-9): 376-383.

Leblance, N.J. and Marques, L. 2019. Anxiety in college: What we know and how to cope. Harvard Health Publishing. Harvard Medical School.

Loiwal, M. 2020, March 2020. 20\% increase in patients with mental illness since coronavirus outbreak: Survey. India Today. https://www. indiatoday.in/india/story/20-per-cent-increasein-patients-with-mentalillness-since-coronavirus-outbreaksurvey-1661584-2020-03-31

Neria, Y., Nandi, A. and Galea, S. 2008. Post-Traumatic Stress Disorder following disasters: a systematic review. Psychological Med., 38(4): 467-480.

Roy, D., Tripathy, S., Kar, S.K., Sharma, N., Veerma, S.K. and Kaushal, V. 2020. Study of knoweledge, attitude, anxiety and perceived mental healthcare need in Indian population during Covid 19 pandemic. Asian J. Psychiatry, 51: 102083. 
Saikarthik, J., Saraswathi, I. and Siva, T. 2020. Risk factors and protective factors of mental health during COVID-19 outbreak and lockdown in adult Indian population- A cross-sectional study. doi: https://doi.org/10.1101/2020.06.13.20130153

Schlesselman, L.S., Cain, J. and DiVall, M. 2020. Improving and restoring the well-being and resilience of pharmacy students during a pandemic. AJPE., 84: ajpe8144. pmid:32665720

Son, C., Hegde, S., Smith, A., Wang, X. and Sasangohar, F. 2020. Effects of COVID-19 on College Students' Mental Health in the United States: Interview Survey Study. J. Med. Internet Res., 22(9): e21279.
Spitzer, R.L., Kroenke, K., Williams, J.B.W. and Lowe, B. 2006. A brief measure for assessing generalized anxiety disorder. Archives of Internal Med., 166: 1092-1097.

Taylor, S. 2019. The psychology of pandemics: Preparing for the next global outbreak of infectious disease. Cambridge Scholars Publishing.

Tracy, M., Norris, F.H. and Galea, S. 2011. Differences in the determinants of posttraumatic stress disorder and depression after a mass traumatic event. Depression and Anxiety, 28(8): 666675. 